\title{
Incentives in Public and Privatized Firms under Incomplete Contracting Situations
}

\author{
Takeshi Miyazaki \\ Department of Economics, Meikai University, Urayasu, Japan \\ Email: tmiyazak@meikai.ac.jp
}

Received April 29, 2012; revised June 1, 2012; accepted July 2, 2012

\begin{abstract}
It is argued that incentives for employees in the public service agencies will necessarily be weak because of the multiple dimensions of products, multiple principals, incomplete contract, and socializing. Some empirical studies refer to incomplete contracting situations as part of the cause of the diminishing of the public sector. This work investigates the effects of privatization and ownership shares on incentive schemes for employees who work for public or privatized firms under incomplete contracting situations. Two main results are obtained. First, the incentive intensity of public firms decreases as the government has more ownership shares, and the social benefit declines. Second, privatized firms offer their employees higher-powered incentive contracts than do public firms.
\end{abstract}

Keywords: Incentives in the Public Sector; Incomplete Contracts; Privatization; Ownership Rights

\section{Introduction}

It has been established in the literature that low-powered incentives in compensation contracts in the public sector arise in such situations as multi-tasking, multi-principal, incomplete contract, and socializing (e.g., [1-4]). Regarding the causes of low incentive intensity in the public sector, multi-task models refer to conflicts among tasks; multi-principal models, to competition among principals; and socializing models, to utility from engaging in the public sectors.

Some empirical studies have also analyzed the factors reducing incentives in the public sector. [5] explains that performance-based organizations that the Gore Plan promoted did not give incentives to employees, since the public agency, which depends on the government for its budgets and thus has lower incentives to maximize profits, cannot commit to a target agreed upon in advance and to performance-related pay. [6] state that performancerelated pay did not improve workers' motivation because the employees distrusted the related appraisal system. [7] purport that privatized firms tend to shift toward payment schemes that are more linked to performance. These works all refer to incomplete contracting situations as part of the cause of the diminishing of the public sector.

This paper investigates how the ownership rights of public and privatized firms, and also privatization, affect the incentive intensity of compensation schemes under incomplete contracting situations. Some theoretical arti- cles discuss whether and when privatization enhances cost-reduction or value-increasing investments, on the basis of the incomplete contracts approach (e.g., $[8,9])$. $[10,11]$ shows that under nationalization, in which the government can adjust production levels ex post, the cost-reduction effort is very low or zero. These studies, however, do not address the relationship between privatization or ownership rights and the incentive schemes that firms offer to employees.

This paper sheds light on the effects of governmental ownership rights and of privatization on incentive schemes under incomplete contracting situations. We obtain two results. First, less ownership shares by the government and larger social benefit from project lead to an increase in the incentive intensity of the contract between a public firm and an employee. Second, a public firm offers a lower-powered incentive contract to its employees than a privatized firm.

This paper is organized as follows. Section 2 sets out the model and sequence of events. Section 3 treats the benchmark cases, and Section 4 discusses the public firm case. Section 5 deals with the model under privatization in addition to the public firm case, and Section 6 presents the conclusions.

\section{The Model}

We consider a government and a firm that are risk neutral, and an employee who is risk averse. There are two 
kinds of firms: a public firm, which is owned by a single manager and the government, and a privatized firm, which is owned by a single private owner and the government. ${ }^{1}$ We assume that only the public firm exists under nationalization, and also only the privatized firm under privatization. The government aims to derive social benefit $B \in \boldsymbol{R}_{+}$from an indivisible project. The government delegates a project to a firm and offers a transfer, $t$, to the firm. The cost of the project is $\theta-x$, where $\theta$ denotes the cost type, and $x$ is the output of the employees' effort, $a \in \boldsymbol{R}_{+}$. The cost-reduction effort contributes to raising the output, $x=a+\varepsilon$, where $\varepsilon$ is the noise, which is a normal random variable with mean 0 and variance $\sigma^{2} .^{2}$ Effort is unobservable for the firm. For example, suppose an employee makes an effort to find a less costly way of constructing a bridge. The output, $x$ is observable and verifiable. For simplicity, two types of cost parameters are assumed, $\theta \in\left\{\theta_{1}, \theta_{2}\right\}$, and $0<\theta_{1}<\theta_{2}$. The low cost parameter, $\theta_{1}$, is drawn with probability $p$, and the high one, $\theta_{2}$, with probability $1-p$.

Firms offer a set of contracts dependent on output $x$. We assume a linear compensation scheme, $w=\alpha+\beta x$, in order to explicitly measure the strength of the incentives, where $\alpha$ and $\beta$, respectively, denote a fixed payment and an incentive intensity. ${ }^{3}$ High intensity implies that the wage is more related to the employee's performance, $x$, and that it is regarded as higher-powered incentive payment. The contract parameters, $\alpha$ and $\beta$, are taken to be observable and verifiable. Disutility of effort is denoted as $\mathrm{d}(a)=k a^{2} / 2$, where $k$ is a parameter that measures the extent of disutility. The disutility function is strictly increasing and strictly convex.

The government owns a fraction, $\gamma \in(0,1]$, of the firm's profits, while its manager owns a fraction, $1-\gamma .{ }^{4}$ As [12] point out, for a public firm, $\gamma$ could be close to one, whereas for a private firm, $\gamma$ is close to zero. ${ }^{5}$

Furthermore, a government can observe the cost parameter, $\theta$, of a public firm ex ante, but not of a privatized one. Since $x$ is verifiable, this implies that the government can, ex post, learn about a public firm's cost, $\theta-x$, as well. As an owner of public firms, the government can know inside information, such as accounted costs and profits, whereas information about the private

\footnotetext{
${ }^{1}$ Although, in practice, the government and many dispersed shareholders own a public firm, for simplicity, the government and a single manager are taken to represent them.

${ }^{2}$ It is assumed that there is no other market for the output of investment, so that output is relation specific and is not useful for trade with other governments or firms.

${ }^{3}[13]$ discuss how limiting attention to a linear compensation scheme is justified in agency problems and other practical situations.

${ }^{4}[13,14]$ take the manager and shareholder to own a fraction of the firm's cash flow.

${ }^{5}$ Many privatized firms are, in fact, owned by both the government and external stakeholders for several years (e.g., [7,15]).
}

firm is not available for the government because inside information can be easily manipulated, and it is tied together with ownership (e.g., $[10,11])^{6}$

The government can also cancel a project launched by a public firm, depending on realized production cost. The government owns a large part of a public firm, knows its cost information, and thus can decide to halt or proceed with the project. $[10,11]$ assumes that the quantity of public goods is efficiently determined ex post by the government under nationalization. On the other hand, if the government is inclined to stop a project in a private firm, then renegotiation must take place between the government and the other owners, but it is difficult to cancel the project. In practice, the government is unable to intervene in a private firm's decisions about production because of its small portion of ownership in the firm (e.g., [7]).

The sequence of decisions is as follows. After $\theta$ is realized, the government decides whether or not to start a project; and if it starts the project, it designs and offers subsidy schemes. Under nationalization, the manager of a public firm decides whether to accept the scheme or to reject it. If it is accepted, the manager, in turn, offers wage contracts to the employees. ${ }^{7}$ Under privatization, a similar process occurs, with the owner-manager making the decisions. Following the contract, the employee exerts effort and output $x$ is realized. Under nationalizetion, the government reconsiders whether to proceed with or terminate the project after observing the realized cost of the project.

At payoff, the government obtains social benefit minus a transfer to the firm and fraction $\gamma$ of the firm's profits. The payoff of the government is given by

$$
g=B-t_{i}+\gamma\left(t_{i}-\left(\theta_{i}-x\right)-\alpha_{i}-\beta_{i} x\right),
$$

where $i=\{1,2\}$ is an index for cost type. The manager or owner-manager of the firm earns part of its net profits, which are subsidy minus project cost and wage payment:

$$
(1-\gamma)\left(t_{i}-\left(\theta_{i}-x\right)-\alpha_{i}-\beta_{i} x\right)
$$

We suppose that the employee's utility is constant absolute risk aversion (CARA). Let cost reduction effort be $a_{i}$ when cost type $\theta_{i}$ is realized. The employee's utility is given by $-\exp \left(-r\left[w_{i}-d\left(a_{i}\right)\right]\right)$, where $r(>0)$ represents the degree of absolute risk aversion. Because output is a normal random variable with mean $a$, the expected utility is expressed as

\footnotetext{
${ }^{6}$ The government does not generally intend to collect information about the firm with which it will contract and is prohibited from entering into a long-term relationship with a particular firm [16, p. 372].

${ }^{7}$ It is assumed that both subsidy schemes and wage contracts are complete contracts and that the enforcement is not dependent on accomplishment or termination of a project.
} 


$$
E\left[-\exp \left(-r\left[w_{i}-d\left(a_{i}\right)\right]\right)\right]=-\exp \left(-r \mathrm{CE}\left(a_{i}\right)\right),
$$

where $\operatorname{CE}\left(a_{i}\right) \equiv \alpha_{i}+\beta_{i} a_{i}-k a_{i}^{2} / 2-r \beta_{i}^{2} \sigma^{2} / 2$ is certainty equivalent. As well known in the literature, an employee can be regarded as maximizing certainty equivalent instead of utility. Suppose that the reservation utility is -1 . Since the manager pursues the least payment as much as possible, the employees' participation constraint is denoted by

$$
\mathrm{CE}\left(a_{i}\right)=0 .
$$

We also assume that $B-\theta_{i}>0$. That is the condition under which it is always socially efficient to launch a project ex ante.

\section{Benchmark Cases}

This section examines two benchmark cases: the model in which the government cannot cancel a project, and the one in which the government can cancel a project after observing the output. In both models, we assume that the government as a social planner can directly choose the employees' effort. As a result, the government gives the manager and employees an amount of payment equal to their reservation wages.

The Socially Efficient Effort When Cancellation Is Impossible

Effort $\alpha$ is chosen so as to maximize the sum of an expected government payoff and manager's payoff:

$$
B-\left(\theta_{i}-a_{i}\right)-k a_{i}^{2} / 2 \text { for } i=1,2 .
$$

The solution of the maximization problem is

$$
a_{i} \equiv a^{*}=1 / k .
$$

This result shows that socially optimal effort is independent of the cost parameter. Because $B-\theta_{i}>0$ from the assumption, the government always launches a project ex ante, even if $a_{i}=0$.

The Socially Efficient Effort When Cancellation Is Possible

This case is different from the first benchmark case in assuming that if output is so detrimental that termination of a project could be ex post efficient for the government, then the government can stop the project. If the government is to complete the project ex post, the social benefit minus the cost of the project would not be negative: $B-\left(\theta_{i}-x\right) \geq 0$. This condition is rewritten as $x \geq \theta_{i}-B$, and we define $X_{i}^{*} \equiv \theta_{i}-B$ as the threshold of whether to complete or terminate the project in the second socially efficient case. An employee's effort is hence chosen so as to maximize

$$
\int_{X_{i}^{*}}^{\infty}\left[B-\left(\theta_{i}-x\right)\right] \mathrm{d} F\left(x \mid a_{i}\right)-k a_{i}^{2} / 2,
$$

where $F\left(t \mid a_{i}\right)$ is the normal conditional distribution function of $t$, given $a_{i}$. The objective function (6) is rewritten as

$$
\left(B-\theta_{i}+a_{i}\right)\left(1-F\left(X_{i}^{*} \mid a_{i}\right)\right)+\sigma^{2} f\left(X_{i}^{*} \mid a_{i}\right)-k a_{i}^{2} / 2,
$$

where $f\left(t \mid a_{i}\right)$ is the density function of $t$ conditional on $a_{i}$. (The derivation of (7) is given in the Appendix.) The project is accomplished with probability

$1-F\left(X_{i}^{*} \mid a_{i}\right)$ and the government then obtains an additional payoff, as expressed in the first and second terms of (7). If the project is cancelled, the government's payoff becomes the third term of (7) and is, therefore, negative.

Maximizing (7) with respect to $a_{i}$, the optimal effort $a_{i}^{* *}$ is obtained as

$$
a_{i}^{* *}=\left(1-F\left(X_{i}^{*} \mid a_{i}^{* *}\right)\right) / k .
$$

(The derivation of (8) is given in the Appendix.) ${ }^{8} \mathrm{~A}$ comparison of (5) and (8) reveals that the effort level is lower when the government is able to cancel a project as opposed to when it is not able to cancel. The reason is that in the second benchmark case, the government does not have to make an employee work hard since it is likely that output $x$ is of no use.

\section{Incentives in the Public Firm}

Under nationalization, the government can influence the public firm's decision about the continuation of a project directly after observing cost performance $\theta-x$. When from (1), the project cost the government must incur after output is realized, $\gamma(\theta-x)$, exceeds the social benefit, cancellation of the project is ex post efficient for the government. Therefore, if $B-\gamma\left(\theta_{i}-x\right)<0$ for $i=1,2$, then the government cancels the project. Depending on whether or not the project is canceled, the government's ex post payoff is decided as follows:

$$
\begin{gathered}
B-t_{i}+\gamma\left(t_{i}-\left(\theta_{i}-x\right)-\alpha_{i}-\beta_{i} x\right) \text { if } x \geq X_{i}, \\
t_{i}+\gamma\left(t_{i}-\alpha_{i}-\beta_{i} x\right) \text { if } x<X_{i},
\end{gathered}
$$

where $X_{i}=\theta_{i}-B / \gamma$. The project in which a cost-efficient firm engages is more likely to be accomplished because $X_{1}<X_{2}$.

The model is solved by backward induction. From (2), a manager solves the following problem:

$$
\begin{aligned}
& \max _{\left(a_{i}, \alpha_{i}, \beta_{i}\right)}(1-\gamma) \\
& \cdot\left[t_{i}-\int_{X_{i}}^{\infty}\left(\theta_{i}-x\right) \mathrm{d} F\left(x \mid a_{i}\right)-\alpha_{i}-\beta_{i} a_{i}\right],
\end{aligned}
$$


subject to participation constraint (3) and an incentive constraint,

$$
\mathrm{CE}^{\prime}\left(a_{i}\right)=\beta_{i}-k a_{i}=0 .
$$

Substituting (3) and (10) into (9), the manager's maximization problem is expressed as, analogous to the derivation of (7),

$$
\begin{aligned}
\max _{a_{i}}(1-\gamma)\left[t_{i}\right. & -\left(\theta_{i}-a_{i}\right)\left(1-F\left(X_{i} \mid a_{i}\right)\right) \\
& \left.-\sigma^{2} f\left(X_{i} \mid a_{i}\right)-\left(a_{i}^{2} k\left(1+r \sigma^{2} k\right)\right) / 2\right] .
\end{aligned}
$$

The second and third terms in the bracket of (11) are the expected additional costs that a public firm must incur when a project is accomplished. The first and fourth terms are independent of the completion of the project.

Analogous to the derivation of (8), in solving (11) with respect to $a_{i}$, we obtain the effort level of the employee:

$$
a_{i}^{N}=\frac{1-F\left(X_{i} \mid a_{i}^{N}\right)-\left(B f\left(X_{i} \mid a_{i}^{N}\right)\right) / \gamma}{k\left(1+r \sigma^{2} k\right)},
$$

where $a_{i}^{N}$ denotes effort at the equilibrium under nationalization. The solution has the following three features: ${ }^{9}$ first, compared with both socially-efficient effort cases, (5) and (8), the level of effort is low due to risk shearing between the manager and the employees. This situation is reflected in the denominator at the right-hand side of (12). Second, the government has more motivetion for completing a project under nationalization than in the second benchmark case, since both the government and the manager share ownership of a public firm. From the definition of $X_{i}$ and $X_{i}^{*}$, we can confirm that the threshold $X_{i}$ becomes lower than $X_{i}^{*}$. This means that because the government's cost burden is limited to its share of ownership, the government is more likely to continue a project under nationalization. Third, because the manager does not care about the social benefit under nationalization, the cost-reduction effort will be low. In the second benchmark case, the government acquires payoffs from social benefit, thereby attempting to make an employee exert effort to realize low production costs. By contrast, under nationalization, the transfer a manager receives from the government is paid independently of the accomplishment of the project, implying that the manager is unlikely to induce the higher level of effort. Using (3), (10), and (12), the terms of a wage contract, $\beta$ and $\alpha$, are given by

$$
\begin{aligned}
\beta_{i}^{N} & =\frac{1-F\left(X_{i} \mid a_{i}^{N}\right)-B f\left(X_{i} \mid a_{i}^{N}\right) / \gamma}{1+r \sigma^{2} k} ; \\
\alpha_{i}^{N} & =\frac{a_{i}^{N^{2}} k\left(\gamma \sigma^{2} k-1\right)}{2} .
\end{aligned}
$$

${ }^{9}$ The second-order condition is assumed to be satisfied:

$$
f\left(X_{i} \mid a_{i}^{N}\right)-B\left(X_{i}-a_{i}^{N}\right) f\left(X_{i} \mid a_{i}^{N}\right) / \gamma \sigma^{2}-k\left(1+r \sigma^{2} k\right)<0 .
$$

We next analyze the effects on incentive intensity of a change in ownership and social benefits. The following results are obtained.

Proposition 1. 1) Incentive intensity for an employee decreases with an increase of government ownership; 2) Incentive intensity for an employee increases with increasing social benefits.

Proof. 1) The derivative of $\beta_{i}^{N}$ with respect to $\gamma$ is, using (10),

$$
\frac{\mathrm{d} \beta_{i}^{N}}{\mathrm{~d} \gamma}=\frac{\partial \beta_{i}^{N}}{\partial a_{i}^{N}} \frac{\mathrm{d} a_{i}^{N}}{\mathrm{~d} \gamma}=k \frac{\mathrm{d} a_{i}^{N}}{\mathrm{~d} \gamma} .
$$

It follows from the normality of $x$ that the derivative of (12) with respect to $\gamma$ is rewritten as

$$
\frac{\mathrm{d} a_{i}^{N}}{\mathrm{~d} \gamma}=\frac{B^{2}\left(X_{i}-a_{i}^{N}\right) f\left(X_{i} \mid a_{i}^{N}\right) / \gamma^{3} \sigma^{2}}{k\left(1+r \sigma^{2} k\right)-\left(1-\frac{B\left(X_{i}-a_{i}^{N}\right)}{\gamma \sigma^{2}}\right) f\left(X_{i} \mid a_{i}^{N}\right)} .
$$

(The derivation of (16) is given in the Appendix.) Since the second-order condition (13) is satisfied, the denominator on the right-hand side of (16) is positive. Therefore, the effect of $\gamma$ on $a_{i}^{N}$ is negative since $X_{i}$ is negative by the assumption $B-\theta \geq 0$ implying that from (15), the derivative of $\beta_{i}^{N}$ with respect to $\gamma$ is also negative. ${ }^{10}$

2) The proof is analogous to proof (1). The derivative of $\beta_{i}^{N}$ with respect to $B$ is equal to (15), except that $\gamma$ is replaced by $B$. If we apply the derivation of (16), the derivative of $a_{i}^{N}$ with respect to $B$ is rewritten as

$$
\frac{\mathrm{d} a_{i}^{N}}{\mathrm{~d} B}=\frac{-B\left(X_{i}-a_{i}^{N}\right) f\left(X_{i} \mid a_{i}^{N}\right) / \gamma^{2} \sigma^{2}}{k\left(1+r \sigma^{2} k\right)-\left(1-\frac{B\left(X_{i}-a_{i}^{N}\right)}{\gamma \sigma^{2}}\right) f\left(X_{i} \mid a_{i}^{N}\right)} .
$$

The denominator on the right-hand side of (18) is positive by the second-order condition (13), and the numerator is also positive from the assumption $B-\theta \geq 0$. Therefore, as the social benefit increases, the employees' effort and incentive intensity increase. Q.E.D.

On the basis of these results, we consider the effect of change in ownership and social welfare on the threshold $X_{i}$. As the government owns more control rights $\gamma$, the

${ }^{10}$ Although the results are dependent on the assumption, we can weaken the assumption and obtain the same results. The term $X_{i}-a_{i}^{N}$ is

rewritten from $X_{i}=\theta_{i}-B / \gamma$ as follows:

$$
X_{i}-a_{i}^{N}=\theta_{i}-B / \gamma-a_{i}^{N}<-\left\{B-\left(\theta_{i}-a_{i}^{N}\right)\right\} .
$$

Equation (17) shows that if the average ex ante profit for the government, $B-\left(\theta_{i}-a_{i}^{N}\right)$, is positive, the right-hand side of (17) is still negative. The government generally launches a project if the average benefit from the project is over zero ex ante, suggesting that the effect of ownership share on effort will be positive in practice. 
threshold becomes large; therefore, the government is less likely to continue with a project. The incentive to reduce the cost of the project decreases, with the implication that the manager will elicit less effort. On the other hand, an increase in social benefits raises the probability of the completion of the project since $X_{i}$ is decreasing in $B$. The manager then elicits a greater cost-reduction effort. $^{11,12}$

\section{Comparison of Incentives before and after Privatization}

In this section, we also consider the privatized firm that belongs to both the government and the owner-manager, who possesses not only the property rights but also control of the firm. We assume that the government cannot alter its decision on a project after the cost is realized.

A private manager finds variables $\left(a_{i}, \alpha_{i}, \beta_{i}\right)$ to solve

$$
\max _{a_{i}, \alpha_{i}, \beta_{i}}(1-\gamma)\left\{t_{i}-\left(\theta_{i}-a_{i}\right)-\alpha_{i}-\beta_{i} a_{i}\right\} \text { for } i=1,2,
$$

subject to (3) and (10), where $t_{i}$ is regarded as given. The solutions are given by

$$
\begin{gathered}
a_{i} \equiv a^{P}=\frac{1}{k\left(1+r \sigma^{2} k\right)}, \\
\beta_{i} \equiv \beta^{P}=\frac{1}{1+r \sigma^{2} k}, \\
\alpha_{i} \equiv \alpha^{P}=\frac{r \sigma^{2} k-1}{2 k\left(1+r \sigma^{2} k\right)^{2}} .
\end{gathered}
$$

The result shows that privatization yields an increase in both the employees' effort and the incentive intensity of wages.

Comparing the employees' efforts and the incentive intensities under nationalization $\left(a_{i}^{N}, \beta_{i}^{N}\right)$ and under privatization $\left(a^{P}, \beta^{P}\right)$, we obtain the following proposition.

Proposition 2. An owner-manager in a privatized firm offers a higher-powered incentive contract than does a manager in a public firm.

Proof. We can confirm by comparing (14) and (19).

Q.E.D.

The effort level under privatization $a^{P}$ is below the socially efficient effort $a^{*}$, since, as shown in the denominator of (19), the manager shares some risk with the employee by offering a low-powered incentive contract. On the other hand, because the project will not be can-

\footnotetext{
${ }^{11}$ We can also show that when governmental ownership becomes larger, the production cost of a public firm decreases.

${ }^{12} \mathrm{We}$ do not discuss here whether or not the government begins a project and offers a subsidy scheme. However, it will be confirmed that under the assumption $B-\theta \geq 0$, the government launches a project if $a_{i}^{N}>0$ at the equilibrium.
}

celed under privatization, as discussed in Section 3, we can make sure by comparison of (14) and (19) that the owner-manager elicits a larger cost-reduction effort and designs a higher-powered incentive scheme than a manager of a public firm does. ${ }^{13}$

\section{Conclusion}

The empirical literature shows that an incomplete contracting situation in the public sector, such as difficulty in committing to targeted objectives and distrust of the appraisal system, results in payment schemes that are less related to performance than are those in the private sector (e.g., [5-7]). This paper investigates what incentive schemes public and privatized firms employ and how ownership interest influences incentive intensity via the incomplete contract model of privatization. We obtain two results. First, when the government holds a significant portion of ownership rights or when the social benefit of a project is small, the manager of a public firm adopts low-powered incentives. The first result mainly comes from the Section 4. Second, the strength of incentives in privatized firms always exceeds that of public firms. The second result comes from the Sections 4 and 5.

\section{REFERENCES}

[1] G. Corneo and R. Rob, "Working in Public and Private Firms," Journal of Public Economic, Vol. 87, No. 12, 2003, pp. 1335-1352. doi:10.1016/S0047-2727(01)00199-2

[2] A. Dixit, "Power of Incentives in Private versus Public Organizations," American Economic Review, Vol. 87, No. 2, 1997, pp. 378-382.

[3] A. Dixit, "Incentives and Organizations in the Public Sector: An Interpretative Review," Journal of Human Resources, Vol. 37, No. 4, 2002, pp. 696-727. doi: $10.2307 / 3069614$

[4] D. Martimout, "Renegotiation Design with Multiple Regulators," Journal of Economic Theory, Vol. 88, No. 2, 1999, pp. 261-293. doi:10.1006/jeth.1999.2556

[5] A. Roberts, "Performance-Based Organizations: Assessing the Gore Plan," Public Administration Review, Vol. 57, No. 6, 1997, pp. 465-478. doi:10.2307/976958

[6] D. Marsden and R. Richardson, "Performing for Pay? The Effects of 'Merit Pay' on Motivation in a Public Service," British Journal of Industrial Relations, Vol. 32, No. 2, 1994, pp. 243-261. doi:10.1111/j.1467-8543.1994.tb01043.x

[7] S. Martin and D. Parker, "The Impact of Privatization: Ownership and Corporate Performance in the UK," Routledge, London, 1997. doi:10.4324/9780203439012

\footnotetext{
${ }^{13}$ We can investigate trade-off between allocative and productive efficiency as $[10,11]$ does. We can obtain the same results as $[10,11]$ : that a public firm ex post attains allocative efficiency but not productive efficiency, while a private firm can attain productive efficiency but not allocative.
} 
[8] D. Bos, "Privatization and Restructuring: An Incompletecontract Approach," Journal of Institutional and Theoretical Economics, Vol. 155, No. 2, 1999, pp. 362-382.

[9] O. Hart, A. Shleifer and R. W. Vishny, "The Proper Scope of Government: Theory and an Application to Prisons," Quarterly Journal of Economics, Vol. 112, No. 4, 1997, pp. 1127-1161. doi:10.1162/003355300555448

[10] K. M. Schmidt, "Incomplete Contracts and Privatization," European Economic Review, Vol. 40, No. 3, 1996, pp. 569-579. doi:10.1016/0014-2921(95)00070-4

[11] K. M. Schmidt, "The Costs and Benefits of Privatization: An Incomplete Contracts Approach," Journal of Law Economics and Organization, Vol. 12, No. 1, 1996, pp. 1-24. doi:10.1093/oxfordjournals.jleo.a023354

[12] M. Boycko, A. Shleifer and R. W. Vishny, "A Theory of Privatization," Economic Journal, Vol. 106, No. 435,
1996, pp. 309-319. doi: 10.2307/2235248

[13] B. Holmstrom and P. Milgrom, "Aggregation and Linearity in the Provision of Intertemporal Incentives," Econometrica, Vol. 55, No. 2, 1987, pp. 303-328. doi: $10.2307 / 1913238$

[14] A. Shleifer and R. W. Vishny, "Politicians and Firms," Quarterly Journal of Economics, Vol. 109, No. 4, 1994, pp. 995-1025. doi:10.2307/2118354

[15] W. Megginson, R. Nash and M. Randenborgh, "The Financial and Operating Performance of Newly Privatized Firms: An International Empirical Analysis," Journal of Finance, Vol. 49, No. 2, 1994, pp. 403-452. doi: $10.2307 / 2329158$

[16] J. Q. Wilson, "Bureaucracy: What Government Agencies Do and Why They Do It," Basic Books, New York, 1989. 


\section{Appendix}

The derivation of (7)

Since $x$ is normal, a truncated expectation of $x$ is as follows:

$$
\begin{aligned}
& \int_{X_{i}^{*}}^{\infty} x \mathrm{~d} F\left(x \mid a_{i}\right) \\
& =\frac{1}{\sigma \sqrt{2 \pi}} \int_{X_{i}^{*}}^{\infty} x \exp \left(-\frac{1}{2}\left(\frac{x-a_{i}}{\sigma}\right)^{2}\right) \mathrm{d} x \\
& =-\frac{\sigma^{2}}{\sigma \sqrt{2 \pi}} \int_{X_{i}^{*}}^{\infty}-\frac{x-a_{i}}{\sigma^{2}} \exp \left(-\frac{1}{2}\left(\frac{x-a_{i}}{\sigma}\right)^{2}\right) \\
& -\frac{a_{i}}{\sigma^{2}} \exp \left(-\frac{1}{2}\left(\frac{x-a_{i}}{\sigma}\right)^{2}\right) \mathrm{d} x \\
& =\sigma^{2} f\left(X_{i}^{*} \mid a_{i}\right)+a_{i}\left(1-F\left(X_{i}^{*} \mid a_{i}\right)\right) .
\end{aligned}
$$

Therefore, (6) is rewritten as (7).

The derivation of $(8)$

For any interior solution, the first-order condition of (7) is given by

$$
\begin{aligned}
& 1-F\left(X_{i}^{*} \mid a_{i}\right)-\left(B-\theta_{i}+a_{i}\right) F_{a}\left(X_{i}^{*} \mid a_{i}\right) \\
& +\sigma^{2} f_{a}\left(X_{i}^{*} \mid a_{i}\right)-k a_{i}=0 .
\end{aligned}
$$

From the normality of $x, F_{a}\left(X_{i}^{*} \mid a_{i}\right)$ and $f_{a}\left(X_{i}^{*} \mid a_{i}\right)$ are, respectively,

$$
\begin{aligned}
F_{a}\left(X_{i}^{*} \mid a_{i}\right) & =-F_{x}\left(X_{i}^{*} \mid a_{i}\right)=-f\left(X_{i}^{*} \mid a_{i}\right) ; \\
f_{a}\left(X_{i}^{*} \mid a_{i}\right) & =\frac{1}{\sigma \sqrt{2 \pi}} \frac{X_{i}^{*}-a_{i}}{\sigma^{2}} \exp \left(-\frac{1}{2}\left(\frac{X_{i}^{*}-a_{i}}{\sigma}\right)^{2}\right) \\
& =\frac{\theta_{i}-B-a_{i}}{\sigma^{2}} f\left(X_{i}^{*} \mid a_{i}\right) .
\end{aligned}
$$

By substituting (21) into (20), (20) is rewritten as

$$
\begin{aligned}
& 1-F\left(X_{i}^{*} \mid a_{i}\right)+\left(B-\theta_{i}+a_{i}\right) f\left(X_{i}^{*} \mid a_{i}\right) \\
& -\left(B-\theta_{i}+a_{i}\right) f\left(X_{i}^{*} \mid a_{i}\right)-k a_{i}=0 .
\end{aligned}
$$

From an easy calculation of (22), (8) is obtained.

The derivation of (16)

The derivative of (12) with respect to $\gamma$ is

$$
\begin{aligned}
& \frac{\mathrm{d} a_{i}^{N}}{\mathrm{~d} \gamma}=\frac{1}{k\left(1+r \sigma^{2} k\right)} \\
& {\left[-\frac{\mathrm{d} F\left(X_{i} \mid a_{i}^{N}\right)}{\mathrm{d} \gamma}-\frac{\mathrm{d}}{\mathrm{d} \gamma}\left(\frac{B}{\gamma} f\left(X_{i} \mid a_{i}^{N}\right)\right)\right] .}
\end{aligned}
$$

The first term of the bracket of (23) is expressed as

$$
\begin{aligned}
& \frac{\mathrm{d} F\left(X_{i} \mid a_{i}^{N}\right)}{\mathrm{d} \gamma} \\
& =\frac{\partial F\left(X_{i} \mid a_{i}^{N}\right)}{\partial X_{i}} \frac{\partial X_{i}}{\partial \gamma}+\frac{\partial F\left(X_{i} \mid a_{i}^{N}\right)}{\partial a_{i}} \frac{\mathrm{d} a_{i}^{N}}{\mathrm{~d} \gamma} .
\end{aligned}
$$

The second term in the bracket of (23) is given by

$$
\begin{aligned}
& \frac{\mathrm{d}}{\mathrm{d} \gamma}\left(\frac{B}{\gamma} f\left(X_{i} \mid a_{i}^{N}\right)\right) \\
& =-\frac{B}{\gamma^{2}} f\left(X_{i} \mid a_{i}^{N}\right)+\frac{B}{\gamma} \frac{\mathrm{d} f\left(X_{i} \mid a_{i}^{N}\right)}{\mathrm{d} \gamma} .
\end{aligned}
$$

The derivative of probability density function $f\left(X_{i} \mid a_{i}^{N}\right)$ with respect to $\gamma$ is

$$
\begin{aligned}
& \frac{\mathrm{d} f\left(X_{i} \mid a_{i}^{N}\right)}{\mathrm{d} \gamma} \\
= & \frac{\partial f\left(X_{i} \mid a_{i}^{N}\right)}{\partial X_{i}} \frac{\partial X_{i}}{\partial \gamma}+\frac{\partial f\left(X_{i} \mid a_{i}^{N}\right)}{\partial a_{i}^{S}} \frac{\mathrm{d} a_{i}^{N}}{\mathrm{~d} \gamma} \\
= & -\frac{1}{\sigma \sqrt{2 \pi}} \frac{X_{i}-a_{i}^{N}}{\sigma^{2}} \exp \left(-\frac{1}{2}\left(\frac{X_{i}-a_{i}^{N}}{\sigma}\right)^{2}\right) \cdot \frac{B}{\gamma^{2}} \\
& +\frac{X_{i}-a_{i}^{N}}{\sigma^{2}} f\left(X_{i} \mid a_{i}^{N}\right) \frac{\mathrm{d} a_{i}^{N}}{\mathrm{~d} \gamma} \\
= & -\frac{X_{i}-a_{i}^{N}}{\sigma^{2}} \cdot \frac{B}{\gamma^{2}} f\left(X_{i} \mid a_{i}^{N}\right) \\
& +\frac{X_{i}-a_{i}^{N}}{\sigma^{2}} f\left(X_{i} \mid a_{i}^{N}\right) \frac{\mathrm{d} a_{i}^{N}}{\mathrm{~d} \gamma} .
\end{aligned}
$$

From (26), (25) is expressed by

$$
\begin{aligned}
& \frac{\mathrm{d}}{\mathrm{d} \gamma}\left(\frac{B}{\gamma} f\left(X_{i} \mid a_{i}^{N}\right)\right) \\
& =-\frac{B}{\gamma^{2}}\left(1+\frac{B}{\gamma} \cdot \frac{X_{i}-a_{i}^{N}}{\sigma^{2}}\right) f\left(X_{i} \mid a_{i}^{N}\right) \\
& +\frac{B}{\gamma} \cdot \frac{X_{i}-a_{i}^{N}}{\sigma^{2}} f\left(X_{i} \mid a_{i}^{N}\right) \frac{\mathrm{d} a_{i}^{N}}{\mathrm{~d} \gamma} .
\end{aligned}
$$

Substituting (24) and (27) into (23) and calculating, we obtain (16). 